\title{
Algorithm of engineering calculation of stability of a multifunctional unit
}

\author{
Alexander Serguntsov ${ }^{1, *}$ and Viktoria Serguntsova ${ }^{2}$ \\ ${ }^{1}$ Chair of processes and machines in agribusiness, Kuban State Agrarian University named after I.T. \\ Trubilin, 350044 Krasnodar, Russia \\ ${ }^{2}$ Department of law, 385000 Adygea State University, Maikop, Russia
}

\begin{abstract}
In the MFA under consideration, in addition to the rotary hoe, a front hopper for fertilization is installed on the front hitch of the tractor. According to G. M. Kutkov, it refers to additional equipment which expands the functionality of the tractor. The assessment of the tractor's load capacity and stability is considered in the works of many educational institutions. We have supplemented these theoretical provisions in relation to the proposed MFA with additional technological equipment of the tractor.
\end{abstract}

\section{Material and methods of the research}

It is known that the installation of machines on the rear hitch of a tractor affects its longitudinal stability determined by the coefficient of use of the reserve of longitudinal stability $\chi_{н}$ [1]. In our MFA the front hopper with the technological material makes an amendment to the theory of the tractor's load capacity as a permissible weight to be hung on it. It is estimated as a percentage of the operating weight of the tractor by its ability to carry the load depending on its location: cantilever at the back, cantilever in front and between the axles. The five criteria of load capacity limits are taken: strength of the tractor frame, durability of undercarriage, pressure on the soil, maintaining the control of the tractor, longitudinal stability [5].

\section{Results of the research}

Justification of the longitudinal stability of the MFA. The calculation of the tractor's load capacity with the MFA is as follows. In our case, the MTZ-80 tractor with a weight $\mathrm{G}_{\mathrm{tr}}=$ $38.5 \mathrm{kN}$, base $\mathrm{L}=2.37 \mathrm{~m}$ and location, $a=0.8 \mathrm{~m}$ between the direction of the weight of the tractor Gtr and the soil reaction $R 2$ of the driving wheel (Fig. 1).

The permissible load of one tire is 16, 9R38 at an air pressure of $0.16 \mathrm{MPa} \mathrm{G}_{\lim }=25.75 \mathrm{kN}$. We take the distance $b=1.717$, and the limit value of the stability coefficient $\chi_{u}=0,4$.

\footnotetext{
*Corresponding author: sasha2008_9191@mail.ru
} 


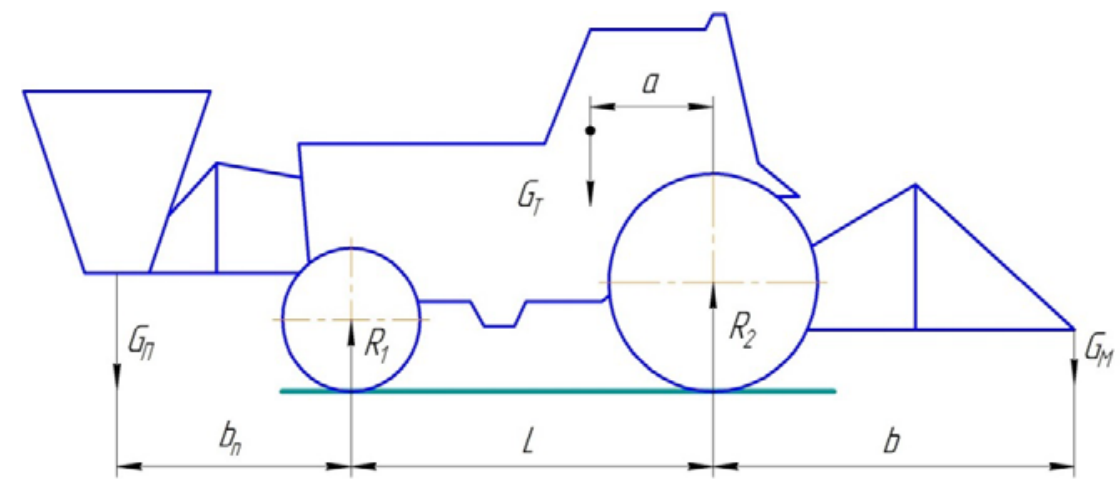

Fig. 1. Diagram of forces and reactions for determining the load capacity of the first and second rows for a wheeled tractor

The most dangerous for longitudinal stability is the movement of the MTA with the machine raised [4]. The criterion of the permissible hitching of this machine under the conditions of longitudinal stability is the coefficient of use of the reserve of longitudinal stability $\chi_{H}$.

$$
\chi_{H}=\frac{G_{M} \cdot b}{G_{T} \cdot a} \leq 0,4
$$

or

$$
\begin{gathered}
G_{M} \leq 0,4 \cdot G_{T} \cdot \frac{a}{b} \\
G_{M} \leq 0,4 \cdot 38,5 \cdot \frac{0,8}{1,717}=7,18 \mathrm{kN}
\end{gathered}
$$

The condition of longitudinal stability is fulfilled at $G_{M} \leq 7,18 \mathrm{kN}$. [1].

We consider the durability of undercarriage in relation to the rear wheels and their tires

Additional force loading the rear wheels from the attached machine:

$$
\begin{gathered}
\Delta Y_{\kappa}=\frac{G_{M} \cdot(L+b)}{L} \\
\Delta Y_{\kappa}=\frac{7,18 \cdot(2,37+1,717)}{2,37}=12,38 \mathrm{kN}
\end{gathered}
$$

normal reaction of the soil to the rear wheels of the tractor:

$$
\begin{gathered}
Y_{\kappa}=\frac{G_{T} \cdot(L-a)}{L} \\
Y_{\kappa}=\frac{38,5 \cdot(2,37-0,8)}{2,37}=25,5 \mathrm{kN}
\end{gathered}
$$

The amount $\Delta Y_{\kappa}+Y_{\kappa}$ must not exceed the permissible load on the rear wheel tires: 


$$
G_{M} \cdot \frac{L+b}{L}+G_{T} \cdot \frac{(L-a)}{L} \leq 2 \cdot G_{l i m}
$$

where $G_{\text {lim }}$ - permissible load on one tire of the rear wheel $G_{\text {lim }}=25,75 \mathrm{kN}$.

$$
12,38+25,5 \leq 2 \cdot 25,75
$$

Thus, inequality (5) is fulfilled ( $37,88 \mathrm{kN} \leq 51,5 \mathrm{kN})$ : the load on the rear wheels is lower than the permissible one.

$$
\begin{gathered}
G_{M} \leq \frac{2 \cdot G_{\text {lim }} L-G \cdot(L-a)}{(L+b)} \\
G_{M} \leq \frac{2 \cdot 25,5 \cdot 2,37-38,5 \cdot(2,37-0,8)}{(2,37+1,717)}=14,78 \mathrm{kN}
\end{gathered}
$$

From the condition of the maximum load on the rear wheels (6), the weight of the hitched machine can be no more than $14,78 \mathrm{kN}$ and according to the condition of longitudinal stability $7,18 \mathrm{kN}$. At the same time, the permissible load capacity of the first type is set equal to $25 \%$ of the operating weight of the tractor, i.e. 9, $63 \mathrm{kN}$.

To load a car with more weight than is acceptable for longitudinal stability, but within the bearing capacity of the tires, we can install ballast loads in the front of the tractor (in our case, a fertilizer spreader). In this case, expression (6) takes the form:

$$
G_{M} \leq \frac{\left[2 \cdot G_{l i m} L+G_{\text {разб }} \cdot l_{\text {разб }}-G_{T} \cdot(L-a)\right]}{(L+b)}
$$

where $G_{\text {разб }}$ - weight of a fertilizer spreader;

$l_{\text {разб }}$ - distance from the front wheel axis to the center of gravity of the spreader.

The permissible load on the front wheels has a maximum value according to the condition of pressure on the ground and the permissible load on the tires.

The longitudinal stability of the MTA with the use of a front hitch is not reduced, since it is almost always used in combination with the hanging of cars on the rear hitch system. Controlling when loading the front wheels with a unit hitched in front of the vehicle under the condition of adhesion to the soil does not deteriorate, but improves. The strength of the front axle and its associated parts must be provided in the design, so it is necessary to find a relationship between the permissible load on the tires of the front wheels and the weight of the machine-tool hung in front of the tractor.

We will calculate the maximum permissible weight of the car, hung on the front hitch of the tractor MTZ-80, which has front wheels equipped with tires 13.6-20. The maximum load for this tire is $G_{\text {lim }}=14,3 \mathrm{kN}$ at air pressure of 2.0 MPa. The operating weight of the MTZ-80 tractor $\mathrm{G}_{\mathrm{tr}}=38.5 \mathrm{kN}$, base $\mathrm{L}=2.37 \mathrm{~m}$ and location, $a=0.8 \mathrm{~m}$. Take the distance $b_{P}=1.1 \mathrm{~m}$.

Let's make an equation of the balance of moments from the forces and reactions of the soil relative to the point of contact of the rear wheel with the soil:

$$
Y_{n} L=G_{T} \cdot a+G_{M} \cdot\left(L+b_{n}\right)
$$


Where from

$$
Y_{n}=\frac{G_{T} \cdot a+G_{M} \cdot\left(L+b_{n}\right)}{L}
$$

or

$$
G_{M} \leq \frac{2 G_{\lim } L-G_{T} a}{L+b_{n}}
$$

where $G_{\text {lim }}$ - permissible load on one tire of the front wheel

$$
G_{M} \leq \frac{2 \cdot 14,3 \cdot 2,37-38,5 \cdot 0,8}{2,37+1,1}=10,66 \mathrm{kN}
$$

From expression (10) the maximum weight of the car being hung according to the condition of the load capacity of the front wheel tires $G_{m}=10,66 \mathrm{kN}$. If we take the weight of the spreader with fertilizers $G_{\text {разб }}=10,66 \mathrm{kN}$, a $l_{\text {разб }}=0,55 \mathrm{~m}$ and substitute them in the expression (7), then the permissible weight $G_{m}$ of the hitched machine under the condition of longitudinal stability will increase to $14,63 \kappa \mathrm{H}$. $\mathrm{kN}$.

$$
G_{M} \leq \frac{[2 \cdot 25,75 \cdot 2,37+10,66 \cdot 0,55-38,5 \cdot(2,37-0,8)]}{(2,37+1,717)}=14,63 \mathrm{kN}
$$

Justification of the transverse stability of the MFA. The stability of the tractor is one of the most important operational properties that characterize its ability to work on slopes without tipping and sliding. To prevent the MFA from tipping over in a static position, the condition must be the following [3]:

- in static $\alpha_{\phi} \leq \alpha_{\text {lim }} ; \beta_{\phi} \leq \beta_{\text {lim }}$.

where $\alpha_{\phi}$ and $\beta_{\phi}$ - angles when the tractor slides

$$
\operatorname{tg} \alpha_{\phi} \leq \varphi_{c} ; \operatorname{tg} \beta_{\phi} \leq \varphi_{z}
$$

where $\varphi_{c}$ and $\varphi_{z}$ - coefficients of adhesion, respectively, in the longitudinal and transverse directions.

The standard values are taken as $\varphi_{c}=0,7$ and $\varphi_{z}=0,6$ [3], therefore, the angles $\alpha_{\phi}=35^{\circ}$ and $\beta_{\phi}=36^{0} 30^{\prime}$ obtained when sliding, respectively.

- in dynamic:

Consider the scheme of external forces acting on the tractor (Fig. 2) [2].

There are additional tipping points due to the static: $y_{\kappa} \alpha_{\kappa}, y_{n} \alpha_{n}$ и $P_{\kappa p} h_{\kappa p}$ where $y_{\kappa}$ and $y_{n}$ - vertical reaction on wheels;

$\alpha_{\kappa}$ and $\alpha_{n}$-displacement of pressure centers because of soil deformation;

$P_{\kappa p}$ and $h_{\kappa p}$ - pull force on the hook, and the height of the trailer point. 


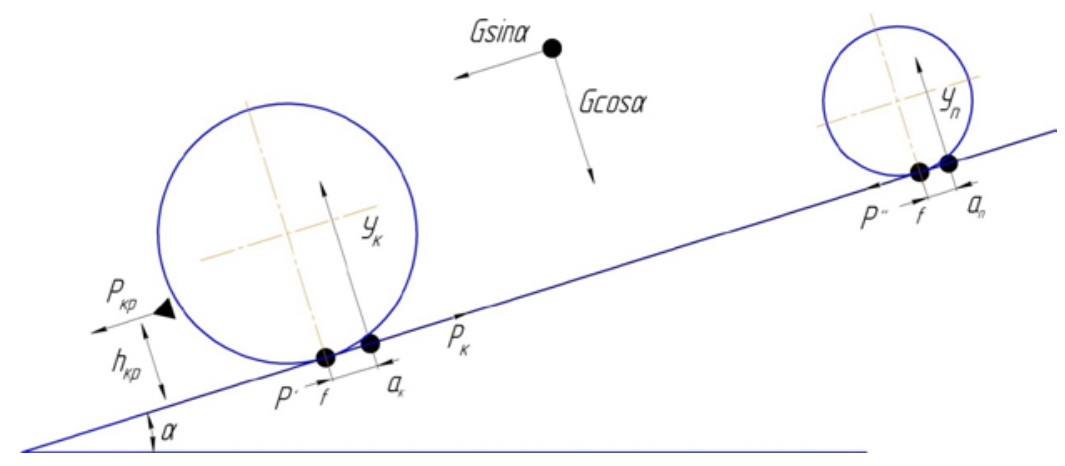

Fig. 2. Diagram of external forces acting on the tractor when working on a slope

The condition of dynamic stability in the longitudinal direction is expressed by the inequality:

$$
P_{\kappa \max } \leq G_{T} \cdot \sin \alpha_{\lim }
$$

The dynamic stability condition is considered:

The diagram of external forces acting on the tractor when working on a transverse slope which is shown in (Fig. 3) is a transverse stability.

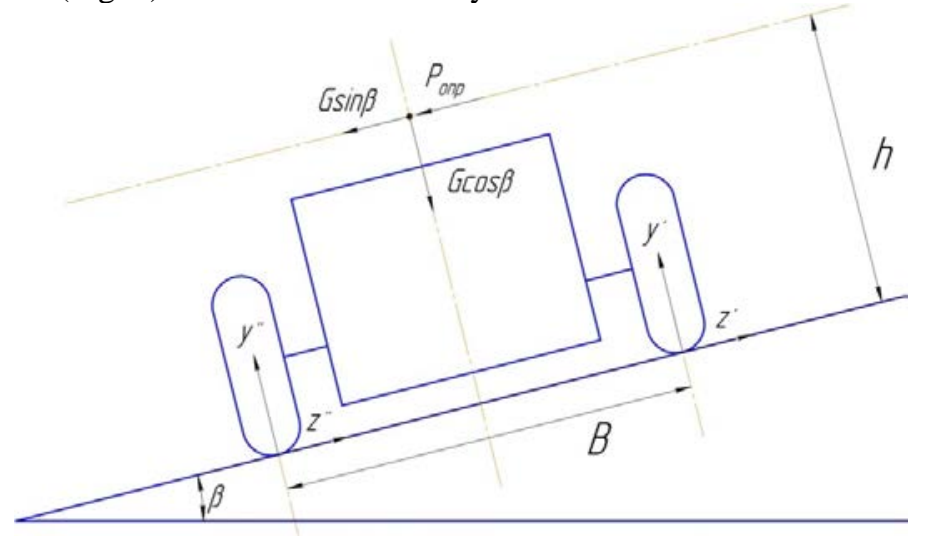

Fig. 3. Diagram of external forces acting on the tractor when turning on a slope

The tipping force can be either a centrifugal force or a force from a trailer or an attached car. The value of the working speed on the turn should not exceed the obtained speed according to the dependence [3]:

$$
V_{\max } \leq \sqrt{g \cdot R \cdot \frac{0,5 B}{h}}
$$

where $V_{\max }-$ velocity of the tractor, $\mathrm{m} / \mathrm{s}$;

$g$ - acceleration of free falling, $\mathrm{m} / \mathrm{s}^{2} ;\left(g=9,81 \mathrm{~m} / \mathrm{s}^{2}\right)$

$G_{\text {тр }}$ - weight of the tractor, $\mathrm{kN}$;

$R$ - radius of the tractor's turn (for MTZ-80 $R=3,6 \mathrm{~m}$ );

$B$ - distance between axles of wheels (fig. 3);

$\beta$ - angle of the slope, degree;

$h$ - height of the tractor, $\mathrm{m}$. 


$$
V_{\max } \leq \sqrt{9,81 \cdot 3,6 \cdot \frac{0,5 \cdot 2,0}{2,47}}=3,78 \mathrm{~m} / \mathrm{c}=13,6 \mathrm{~km} / \mathrm{h}
$$

\section{Conclusions}

For the MTZ-80 tractor, the maximum speed on the turn should not exceed $5.1 \mathrm{~m} / \mathrm{s}(18.5$ $\mathrm{km} / \mathrm{h}$ ), and according to the calculations performed, it can be concluded that for the proposed MFA for feeding winter crops with simultaneous harrowing, the maximum speed on the turn should not exceed $3.78 \mathrm{~m} / \mathrm{s}$ or $13.6 \mathrm{~km} / \mathrm{h}$, which is within the maximum speed limits of the tractor used.

\section{References}

1. Kutkov G. M.,Tractors and automobiles. Theory and technological properties : textbook, $2^{\text {nd }}$ ed., reprint. and add, M.: 2014, 505 p.

2. Sednev, N. A. Kinematics of the needle disk when moving with braking, Tractors and agricultural machines, 1979, № 6, P. 18-19.

3. M. A. Smirnov, V. V. Belyakov, S. M. Kokorin, Fundamentals of tractor theory, Methodical instructions. Saint Petersburg, 2008, 27 p.

4. Unit for tillage with fertilization/ Patent for the invention RUS 2629265. publ. 28.08.2017. Authors: Maslov G. G., Serguntsov A. S.

5. Sergey K. Papusha ${ }^{1}$, Azamat E. Bogus, Vladimir I. Konovalov, Interaction of rotary working body of roller type with the object of processing / Sergey K. Papusha ${ }^{1}$, Azamat E. Bogus, Vladimir I. Konovalov, MATEC Web of Conferences 224, 05007 (2018). 